\title{
SOIL TILLAGE FOCUSING ON THE REDUCTION OF WATER EROSION OF SOIL IN THE CULTIVATION OF SELECTED FIELD CROPS
}

\author{
Petr NOVÁK, Faculty of Engineering, University of Life Sciences Prague, Kamycka 129, 16521 Prague 6 - Suchdol, Czech \\ Republic, novakpetr@tf.czu.cz (corresponding author) \\ Jiř́ MAŠEK, Faculty of Engineering, Czech University of Life Sciences Prague, Kamycka 129, 16521 Prague 6 - Suchdol, Czech \\ Republic, masekj@tf.czu.cz \\ Josef HŮLA, Faculty of Engineering, Czech University of Life Sciences Prague, Kamycka 129, 16521 Prague 6 - Suchdol, Czech \\ Republic, hula@tf.czu.cz \\ Lukáš BENEŠ, Faculty of Engineering, Czech University of Life Sciences Prague, Kamycka 129, 16521 Prague 6 - Suchdol, \\ Czech Republic, benes@tf.czu.cz \\ Jitka KUMHÁLOVÁ, Faculty of Environmental Sciences, Czech University of Life Sciences Prague, Kamycka 129, 16521 Prague \\ 6 - Suchdol, Czech Republic, kumhalova@fzp.czu.cz
}

\begin{abstract}
Water erosion is a problem of global significance. Water erosion destroys or damages a vast expanse of usable agricultural land every year. Conditions in the Czech Republic are characterized by high average slope of the land. It is reported that approximately half of land in the Czech Republic is threatened by water erosion. Water erosion is a natural process that cannot be fully prevented. In case of agricultural land an important option is suitable tillage, which may reduce symptoms of water erosion. The problem of water erosion of agricultural land is growing in the Czech Republic, which is mainly caused by the growth of wide areas of crops (maize). This is due to expansion of biogas power plants using parts of maize silage.

The aim of paper is to evaluate and assess the crop stand establishment in conditions of resistance to water erosion. For this purpose, a field experiment was set up. This experiment affects the most widely used methods of maize cultivation in Central Bohemia region. It consists of six variants of crops and technologies stand establishment and control treatment without vegetation. To determine the surface runoff and erosive wash was used measurement by runoff microplots.

From processed measurement the positive impact of reduced tillage on soil resistance to water erosion results can be confirmed. The consequence is a reduction of surface runoff and especially erosive washes of soil. Impact of ground cover with organic matter is favorable, even in case of conventional tillage. The results of the experiment are directly applicable to agricultural practices. Results of the experiment were used for the legislative recommendations of appropriate technology (wide-row crops on slopes).
\end{abstract}

Keywords: erosive wash, surface tillage methods, water runoff.

\section{INTRODUCTION}

Main risks of agricultural land include water and wind erosion, loss of organic matter in the soil, reducing the biological activity in the soil and soil compaction (Hůla et al., 2010). Degradation of agricultural land usually combines these phenomena. A causal relationship between these adverse effects can be also found. Land degraded by one of these phenomena loses resistance to other risks. Any land management system should be constantly at the forefront of preserving soil fertility and its ecological functions.

Soil erosion is a natural process occurring in all soils. There is eroding soil surface, removal of soil particles and the consequent deposition of such particles at other locations. The landscape is largely transformed by the forces of erosion and mechanical weathering of rocks. The main factors of weathering processes are water, wind and temperature extremes. There are more kinds of erosion processes, on agricultural soils occur mostly water and wind erosion (Morgan, 2005).

The biggest danger for soil represent an inappropriate manner based stands wide-row crops, especially in the initial stage of development. As mentioned in the introduction, in the Czech Republic, it is primarily maize crop planted on sloping land. Cereal, temporary grassland, grasslands are damaged less. The least damage is in forests. Most of studies in this section deal with the issue of organic matter on the soil surface. This organic matter on the surface may have different origins. It may be previous crop debris, blunted second growth, and the frozen (deadweight) crops or deliberately applied organic matter. Conservation technologies used primarily organic matter on the surface.

Beneficial effects of soil conservation technologies to reduce surface water runoff and increase infiltration of water into the soil show Zhang et al. (2014). Anken et al. (2004) found that technology, minimization of soil erosion, soil loss 
decreased by half to two thirds. What is important for reducing the risk of water erosion is a targeted retention of crop residues on the soil surface (previous crop harvest residues, biomass, intercrops). Increased infiltration of long-Zero cultivated soils compared to soils ploughed annually justifies Baumhard a Jones (2002), destruction of soil aggregates in conventionally treated soils. Tillage also plowed crop residues into the soil, so apply the protective function.

As stated by Franzluebbers (2002), organic matter in soil is a key factor in the preparation of soil and water infiltration into the soil. Organic matter content is determined by a parameter of soil carbon content. Reicosky et al. (2005) note, that the loss of soil carbon and soil displacement during processing can cause soil degradation and soil erosion. They also state that soil plays an important role in carbon storage. Tillage, which causes loss of carbon, is in direct contact with the soil characteristics and environmental problems (Paustian et al., 1997).

\section{MATERIALS AND METHODS}

A field trial has been established in 2009 for the purpose of measuring water erosion in Nesperská Lhota, which is located on the border Benesovské and Vlašimské hills. The experiment was based on light, sandy loam Cambisol at an altitude of $420 \mathrm{~m}$, average slope of land $5.4^{\circ}$. The field experiment consists of seven basic variants. Each option has an area of $300 \mathrm{~m} 2$ and size variations are $6 \mathrm{~m} \times 50 \mathrm{~m}$, where the longer side is oriented along the fall line. Individual variations represent different technologies stand establishment - maize (Zea mays L.) and oat (Avena sativa L.). Maize consists of four variants and oats of 2 variants. The seventh option then is black fallow.

Variants of the experiment:

1. Conventional technology - autumn ploughing+ sowing maize.

2. Conventional technology - autumn ploughing+ sowing oats.

3. Conventional technology - autumn ploughing + sowing maize + cereal between rows.

4. A variant without tillage - maize with spring reduced tillage of the soil - crop stubble after harvest, spring tillage with chisel cultivator.

5. A variant without tillage, direct sowing oats.

6. A variant without tillage, maize in the frozen intercrops without soil preparation spring - autumn reduced tillage + sowing intercrops, spring sowing only.

7. A variant "black fallow" - autumn plowing, spring tillage blade cultivator to a depth of $0.15 \mathrm{~m}$ maintained without vegetation - herbicide application.

On each variant of the experiment were after sowing cereals and maize installed 4 runoff microplots (Figure 1). Microplot is defined by walls of steel sheet with a thickness of $1.5 \mathrm{~mm}$. Sheet walls were pressed into the soil so that the $0.08 \mathrm{~m}$ height of the wall is found in soil and 0.04 meters protrudes above the ground. The lower part of microplot is drained into a drain collector and further conveyed to the buried-lying plastic collecting container (a canister with volume of $10 \mathrm{dm}^{3}$ ).

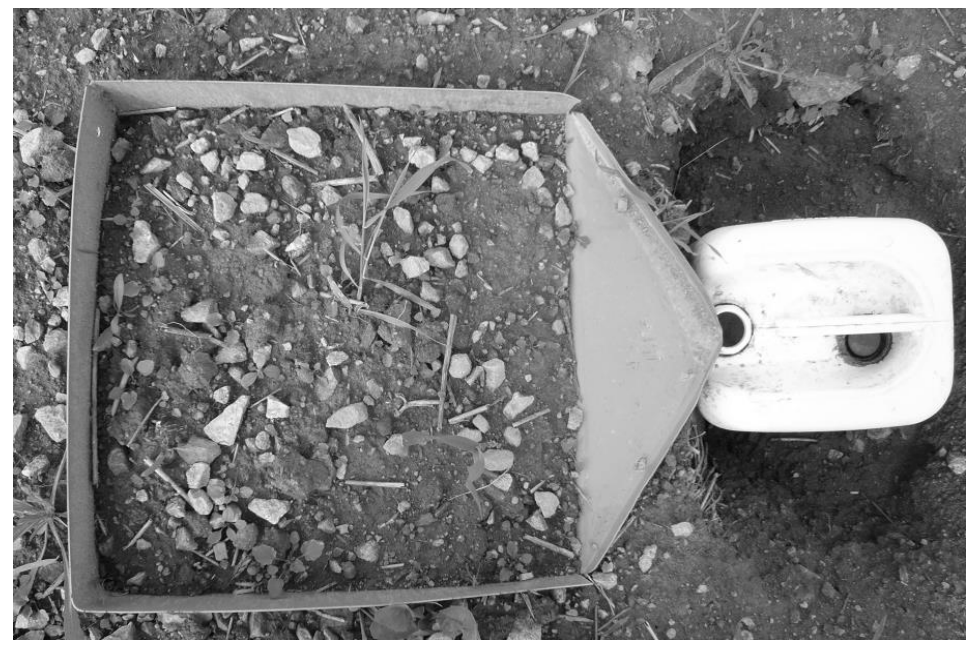

Figure 1. Drain microplot with drip area $0.16 \mathrm{~m}^{2}$

\section{RESULTS AND DISCUSSION}

The first erosional event of the season in 2014 was a thunderstorm at night from 9th to 10th May. It was a storm accompanied by torrential rain with an intensity of up to $80 \mathrm{~mm} / \mathrm{h}$. Total rainfall featured $22 \mathrm{~mm}$. The storm occurred when the land was without sufficient vegetation cover. The crop was freshly sown maize. The soil was in this period in particular variants with maize under-protected. The measurement results are shown in Figures 2 and 3. Among the results of measurements of a surface runoff statistically significant differences were found. Tukey HSD test $(\alpha=0.05)$ showed statistically significant differences in surface runoff between variants with ploughing and without ploughing. Other significant differences were noted between variants with plowing between them. In particular no-tillage variants 5 and 6 , partly option 4) excelled lower surface runoff versus variants with plowing $(1,2,3)$. The results of measurements of 
erosive wash confirm the positive contribution of no-tillage technologies to erosion parameters. Tukey HSD test showed statistically significantly greater erosive wash in variants 1 and 7 in comparison with other variants.

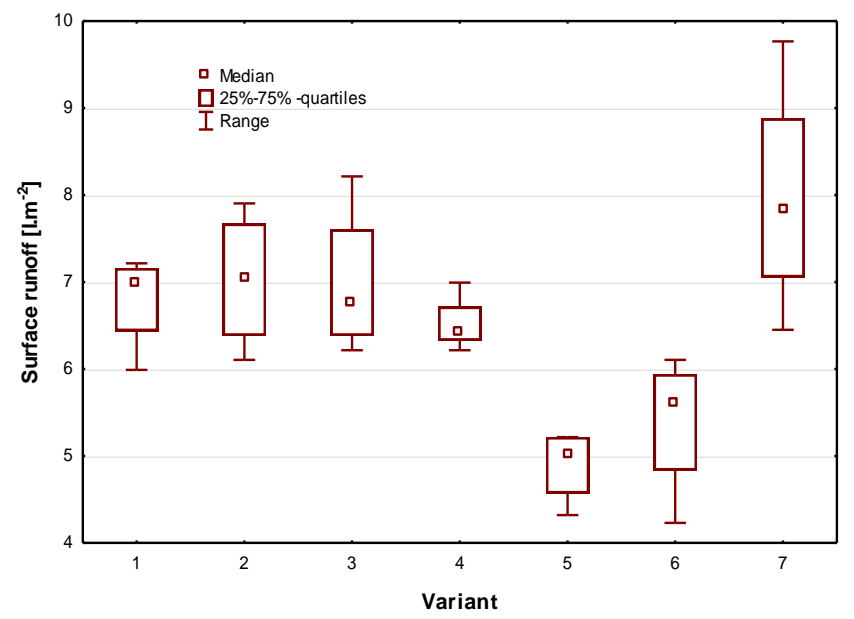

Figure 2. Surface runoff during storm 9/10. May, 2014

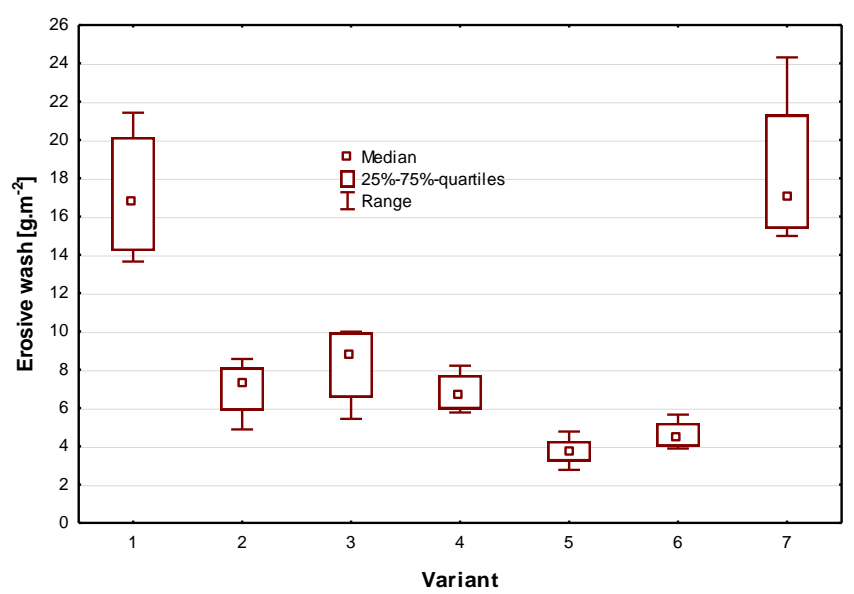

Figure 3. Erosive wash during storms 9/10. May, 2014

Other registered event in 2014 was the storm on July 29 (Fig. 4 and 5). This storm had a short-term high intensity recorded during measurement - up to $350 \mathrm{~mm} / \mathrm{h}$. A summary of the fallen precipitation accounted $40 \mathrm{~mm}$. The measurement process was affected by extreme weather in June (as of July rainfall $220 \mathrm{~mm}$ ). Nevertheless, risk of variant 7 is evident; it had the highest surface runoff. Statistically significant differences was found between variant 7 and other variants during testing of surface runoff using Tukyey HSD test The soil was affected on all variants of high-washes and surface runoff from the June rains. The soil had minimal roughness until the end of the season 2014. A statistically significant difference was found between the variant 7 and other variants (except 1) and also between variant 1 and others (except 7). Tukey HSD test was again used during testing values of erosive wash. The results however confirm the conclusions of previous measurements. The soil must be covered with organic material in any form.

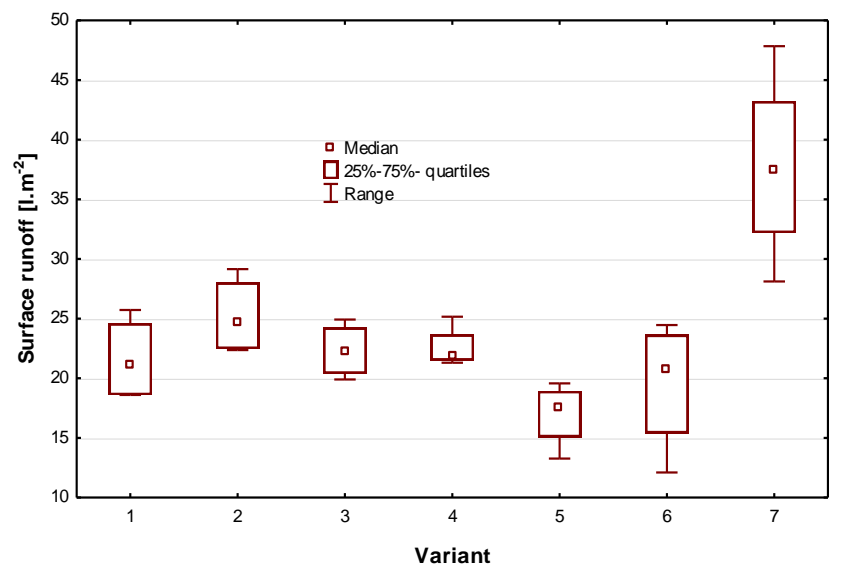

Figure 4. Surface runoff during storm on July 29, 2014. 


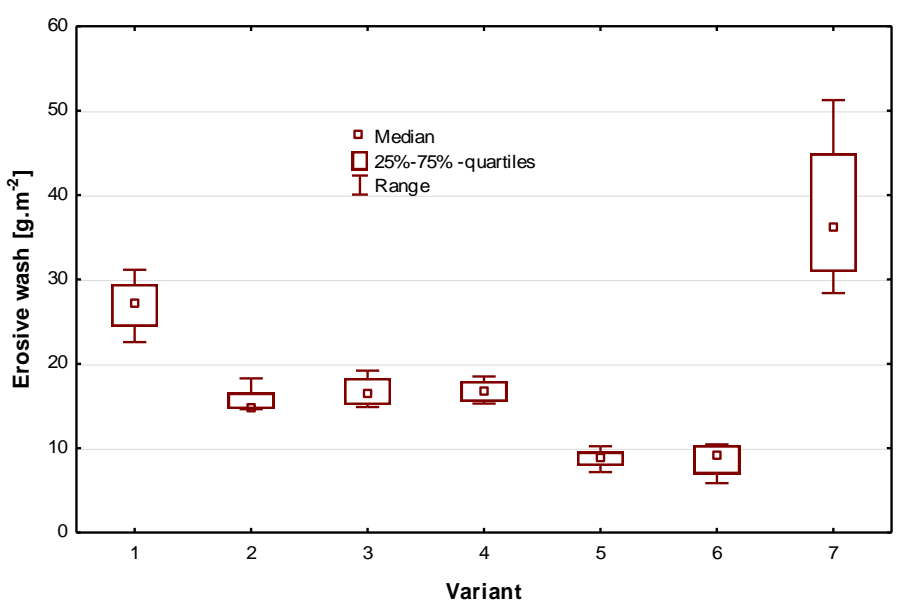

Figure 5. Erosive wash during storm on July 29, 2014.

Terzoudi (2007) reportes that no-till technologies may have higher surface runoff despite covering the surface with organic material. The author presents the possible effects by soil type. Within the field experiment conducted technology like no-till, however, has demonstrated a beneficial effect on surface runoff at most measurement using two basic methods. This is confirmed by Santos (2003), who confirmed the beneficial effect of no-till technology to surface runoff.

Akinyemi, Adedeji (2004) investigated the effect of tillage (no-till, conservation and processing plough tillage) to water infiltration into the soil. Results showed significant differences in infiltration for methods used for tillage. Although no significant difference between classical and preservative treatment has not been observed, but no-till technology showed significant differences compared to other methods and the highest infiltration rate.

Measurement of erosive wash brought completely unambiguous confirmation of the benefits of no-till technologies for soil protection in all seasons of measurements. The results of soli washes during intense rains are consistent with these of Rasmussen (1999) and other authors (Truman, Shaw, Reeves, 2005).

\section{CONCLUSIONS}

Selection of an appropriate system of tillage, especially on sloping land, can reduce the risk of excessive washes away soil, which can be considered as the most pernicious manifestation of water erosion on agricultural land. Nevertheless, in no case be expected that any method of tillage erosion processes can be eliminated.

The measurement results clearly demonstrate the importance of soil organic matter coverage, as an effective means to reduce erosion processes. Organic matter on the soil surface can have very diverse character. However, in any form it acts as a protective element. As noted, the risk in terms of excessive water erosion represents wide rows crops.

Input hypotheses have been largely confirmed. Clearly has been demonstrated positive effect of no-till technologies to erosive washes reduction. In case of runoff their meaning is not entirely clear. However, it should be noted that in terms of soil damage is the loss far more serious than a simple surface runoff.

Acknowledgements. Supported by the Ministry of Agriculture of the Czech Republic - Project no. QJ1520028.

\section{REFERENCES}

1. Anken, T., Weisskopf, P., Zihlmann, U., Forrer, H., Jansa, J., Perhacova, K. 2004. Long-term tillage system effects under moist cool conditions in Switzerland. Soil \& Tillage Research, Vol. 78, pp. 171-183. http://dx.doi.org/10.1016/j.still.2004.02.005

2. Akinyemi, J. O., Adedeji, A. O. 2004. Water Infiltration Under No-tillage, Minimum Tillage and Conventional Tillage Systems on a Sandy Loam Alfisols. ASAE/CSAE Annual International Meeting, Paper Number: 042111.

3. Baumhard, R. L., Jones, O. R. 2002. Residue management and paratillage effects on some soil properties and rain infiltration. Soil \& Tillage Research, Vol. 65, pp. 19-27. http://dx.doi.org/10.1016/S0167-1987(01)00273-2

4. Franzluebbers, A. J. 2002. Water infiltration and soil structure related to organic matter and its stratification with depth. Soil \& Tillage Research, 66, pp. 197-205. http://dx.doi.org/10.1016/S0167-1987(02)00027-2

5. Hůla, J. 2010. The impact of non-traditional technologies tillage on soil environment. VUZT v.v.i., Praha, 60 p. (in Czech).

6. Morgan, R. P. C. 2005. Soil erosion and conservation. Third Edition. Blackwell Publishing Company, Malden, USA. p. 304.

7. Paustian, K., Collins, H. P., Paul, E. A. 1997. Management controls on soil carbon. In: Soil Organic Matter in Temperate Agroecosystems. CRC Press, Boca Raton., pp. 15-49.

8. Rasmussen, K. J. 1999: Impact of ploughless soil tillage on yield and soil quality: A Scandinavian review. Soil \& Tillage Research, 53, pp. 3-14. http://dx.doi.org/10.1016/S0167-1987(99)00072-0

9. Reicosky, D. C., Lindstrom, M. J., Schumacher, T. E., Lobb, D. E., Malo, D. D. 2005. Tillage-induced CO2 loss across an eroded landscape. Soil \& Tillage Research, Vol. 81, pp. 183-194. http://dx.doi.org/10.1016/j.still.2004.09.007 
10. Santos F. L., Reis J. L., Martins O. C., Castanheira N. L., Serralheiro R. P. 2003. Comparative Assessment of Infiltration, Runoff and Erosion of Sprinkler Irrigated Soils. Biosystems Engineering, Vol. 86, Iss. 3, pp. 355-364. http://dx.doi.org/10.1016/S15375110(03)00135-1

11. Terzoudi, Chr. B., Gemtos, T. A., Danalatos, N. G., Argyrokastritis, I. 2007. Applicability of an empirical runoff estimation method in central Greece. Soil \& Tillage Research, 92, pp.198-212. http://dx.doi.org/10.1016/j.still.2006.03.002

12. Truman, C. C., Shaw, J. N., Reeves, D. W. 2005. Tillage efects on rainfall partitioning and sediment yield from an ultisol in central Alabama. Journal of Soil and Water conservation, Vol. 60, pp. 89-98.

13. Zhang, G. H., Liu, G. B., Zhang, P. C. 2014. Influence of vegetation parameters on runoff and sediment characteristics in patterned Artemisia capillaris plots. Journal of Arid Land, Vol. 6, pp. 352-360. http://dx.doi.org/10.1007/s40333-013-0224-5 